American Journal of Infectious Diseases 7 (2): 45-50, 2011

ISSN 1553-6203

(C) 2011 Science Publications

\title{
The Trend of Smoking Behavior and its Relation to Health Knowledge among Medical and Literature Colleges
}

\author{
${ }^{1}$ Wijdan Akram, ${ }^{1}$ Selwa Elias Yacoub, \\ ${ }^{2}$ Ali Abed Ali Al Saedi and ${ }^{1}$ Yousif Abdul Raheem \\ ${ }^{1}$ Department of Community Medicine, \\ Al Kindy College of Medicine, University of Baghdad, Baghdad, Iraq \\ ${ }^{2}$ Department of Community Medicine, \\ Al Nahreen Medical College, Baghdad, Iraq
}

\begin{abstract}
Problem statement: Smoking is a major public health problem all around the world, especially in developing countries when smoking behavior among college students is a major concern to the society. Object of this study to estimate the prevalence of smoking among university students of medical and literature colleges and to assess the students' knowledge about the health effects of smoking and attitudes towards public action against smoking. Design: cross sectional study. Setting: AlKindy Medical College, Baghdad Medical College and Baghdad literature collage/University of Baghdad for the period from first of March till 1st of April 2010. Approach: A random sample of 252 students of 1 st and 2nd stages at the above colleges, 124 Literature students and 128 students in two Medical colleges, had been selected and subjected to the modified Arabic version of the World Health Organization (WHO), standard questionnaire for young people, to study their knowledge, attitudes and practices of smoking. All the information elicited from the questionnaire was collected and analyzed. The statistical differences between literature students and medical students were estimated. Results: The prevalence of current smoking was 58, 60\% for cigarettes, 65, 56\% for sheesha) for Medical and Literature students respectively. Friends were the main source of the first cigarette $(69 \%),(62 \%)$ among students of the literature college and those of the medical college, respectively. followed by parents. Level of awareness of the injurious nature of smoking found to be very high among both medical $100 \%$ and literature students $94 \%$, while $(74 \%)$ of medical student and only $(51.3 \%)$ of Literature student Agree with prevention of smoking advertising activity. Conclusion/Recommendations: Smoking still constitutes a major problem among Baghdad university students, in spite of high level of awareness to it's hazards. This may call for an urgent action to be undertaken by health sectors in accordance with other governmental and nongovernmental sectors to apply new strategies aimed at smoking cessation in the community through implementation of an antismoking program for school and college students, adaptation of legislation aimed at restriction of this behavior, through forbidden smoking in general places, increase taxes, advertisement being directed toward exploring the unhealthy effects of smoking.
\end{abstract}

Key words: Smoking prevalence, smoking habits, cigarette smoke, psychological reasons, literature colleges, polycyclic aromatic hydrocarbon, anti-smoking education program, World Health Organization (WHO)

\section{INTRODUCTION}

Smoking is the method of consumption tobacco in to the body by many role of consumption. Cigarette smoke contains more than 4000 chemical substances, more than 60 carcinogens. Polycyclic aromatic hydrocarbon and nitro amines are potent carcinogens and mutagens (Van Oort et al., 2006).

As of 2000, smoking is practiced by 1.22 billion people. Assuming no change in prevalence, it is predicted that 1.5-1.9 billion people will smoke in 2025 . It is estimated that by $2025,75 \%$ of early deaths

Corresponding Author: Wijdan Akram, Department of Community Medicine, Al Kindy College of Medicine, University of Baghdad, Baghdad, Iraq 
in developing countries will be due to smoking-related illnesses. The World Health Organization (WHO) states that "Much of the disease burden and premature mortality attributable to tobacco use disproportionately affect the poor". Of the 1.22 billion smokers, 1 billion of them live in developing or transitional economies. Rates of smoking have leveled off or declined in the developed world (Kulikoff, 1986). In the developing world, however, tobacco consumption is rising by $3.4 \%$ year $^{-1}$ as of 2002 (Al-Kilani, 2001).

Each year, tobacco products kill some 3 million people worldwide and this number is increasing WHO estimates that, unless current smoking patterns are reversed, by the decade 2020-2030 tobacco will be responsible for 10 million deaths per year, $70 \%$ of them occurring in developing countries (Brown et al., 2003). Smoking kills over 400,000 people a year "more than one in six people in the United States" making it more lethal than AIDS, automobile accidents, homicides, suicides, drug overdoses and fires combined. The World Health Organization has reported widely differing prevalence of smoking among young people in the Arab countries: $7 \%$ in Oman, $18 \%$ in Kuwait, $23 \%$ in Iraq, $25 \%$ in Saudi Arabia and Jordan, $31 \%$ in Syrian Arab Republic, $43 \%$ in Yemen and 53\% in Lebanon (Van Oort et al., 2006). However, the trend and pattern of smoking as well as the quitting rate especially among college students are largely unknown in many of these countries

Cigarette smoking is now most common between the ages of $16-24$ years ( $42 \%$ in both sexes). Nicotine is highly addictive stimulant that can lead to dependence, tolerance and withdrawal effects. Smoking nearly always begins in adolescence for psychological reasons and, once it is a regular habit, the pharmacological properties of nicotine play an important part in persistence, conferring some advantage to the smoker's mood. Initiation of smoking behavior among school and college students is a major concern to the society. Despite knowledge based intervention, global trends seem to indicate an increasing smoking habit among the students. There has been a dramatic increase over the past decade in the numbers of college-age smokers (Kulikoff, 1986). Several studies report that the prevalence of smoking increases from the first year to the final year among university students, which underlines the fact that the early years at university are important for targeting anti-smoking activities (Van Oort et al., 2006). Students who enter college as nonsmokers are $40 \%$ less likely to begin smoking if they live in a smoke-free campus (Chassin et al., 2002). Smoking is generally five times higher among men than women, Special Report of the Health. However the gender gap declines with younger age (Heckenwelder and Reichel, 2003). In developed countries smoking rates for men have peaked and have begun to decline, however for women they continue to climb (Gottsegen, 1940). It is estimated that the US spends an astounding $\$ 50$ billion each year on smoking-related health costs. Smoking may be even more dangerous now than 30 years ago, most likely because the lower tar and nicotine levels in most cigarette brands cause people to inhale more deeply. In one study only $42 \%$ of male lifelong smokers reached the age of 73 compared to $78 \%$ of nonsmokers. People who are exposed to second-hand or side-stream smoke are also at risk.

Physicians occupy a key position in this regard, as they are uniquely placed to lead smoking cessation programs in the community (Balls, 1962). The aim of study:

- To estimate the prevalence of smoking among university students of Medical and literature colleges

- To assess the students' knowledge about the health effects of smoking and attitudes towards public action against smoking

- To evaluate the differences in knowledge, attitude and behavior related to smoking between medical students and literature

\section{MATERIALS AND METHODS}

Across sectional study has been conducted at AlKindy Medical College, Baghdad Medical College and Baghdad literature collage/University of Baghdad for the period from first of March till 1st of April 2010.

A random sample of 252 students of first and second stage including 128(78(60.94\%) male, $50(39.06 \%)$ female) students from Baghdad medical college, Al- kindy college of medicine and 124 students (71(57.26\%) male, 53(42.74\%) female) from literature college. All students had completed a self administered Arabic version of the World Health Organization (WHO), standard questionnaire for young people. The questionnaire had been designed to elicit information related to type of smoking, history of smoking (Age at initiation of smoking), source of first cigarette, attitude toward smoking cessation, health knowledge related to undesirable effect of smoking and opinion about the community tools to stop smoking. 
Statistical analysis: All data were introduced into a personalized computer and analyzed using Minitab version 13 statistical software. Frequency distributions for selected variables were assessed and statistical differences between medical and literature students were evaluated using $\mathrm{x}^{2}$ test. $\mathrm{P}$ value $\leq 0.05$ was the level of significance in this study

\section{RESULTS}

No significant difference had been found between medical and literature student concerning current smoking ( $\mathrm{p}$ value 0.732 ) for both male ( $\mathrm{p}$ value 0.629 ) and female ( $\mathrm{p}$ value 0.065 ) as shown in Table 1.

On the other hand there is no significant differences had been found (Table 2) among smokers of both colleges in term of age of starting smoking ( $p$ value 0.729 ) and smoking in college ( $p$ value 0.65 ). Cigarette smoking ranked first for both groups of students (64 and 81\%), followed by the sheesha (the traditional Arabic smoking pipe) (65 and 56\%), for Medical and Literature colleges respectively.

The predominant influence to initiate smoking revealed in the source of first cigarette found to be related to friends for both medical $(62 \%)$ and literature $(69 \%)$ students while parents were reported as the second frequent source for the influence of smoking for medical (22\%) and for literature (25\%) students.

The level of awareness in respect to the hazardous effect of smoking habit being a risk factor to many health problems, found to be very high (Table 3 ) among both medical, (100\%) and (98\%) of literature students, beside $(100 \%)$ of medical and $70.1 \%$ of literature students know that physical activity may reduce smoking while only (29.6\%) of medical and (12\%) of literature students know that smoking could be reduced by some medication. On the other hands only $(28.1 \%)$ of medical and $(24.1 \%)$ of literature students respond positively to the information that people smoke for calming down and (64.8\%) of medical and 54\%) of literature students to that people smoke due to dependence. Regarding source of information associated with smoking, (100\%) of medical and only $4 \%$ ) of literature students reported that college being one of them. The attitude of students represented by their desire to stop smoking reflected in the answers of $53.2 \%$ of medical and $45.8 \%$ of literature students. The information that the students already had about smoking reported to be enough to start stopping smoking among only $38.2 \%$ of medical and $4 \%$ of literature students.

Table 1: distribution of the studied sample according to their smoking status in both genders

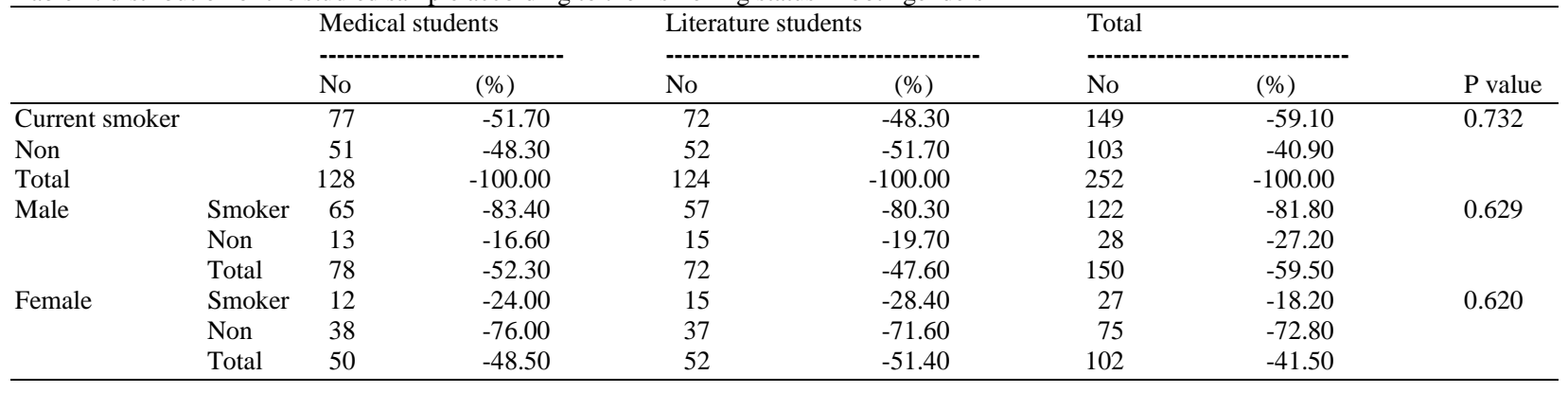

Table 2: History of smoking among current smoker of medical and literature students

\begin{tabular}{|c|c|c|c|c|}
\hline & & $\begin{array}{l}\text { Medical students } \\
\text { (smoker) } \mathrm{n}=77 \\
\text { No }(\%)\end{array}$ & $\begin{array}{l}\text { Literature students } \\
\text { smoker) } n=72 \\
\text { No }(\%)\end{array}$ & $P$ value \\
\hline \multirow[t]{2}{*}{ When did you start smoking } & Before age of 18 & $9(7.03)$ & $11(8.87)$ & \\
\hline & After age of 18 & $68(53.12)$ & $61(49.19)$ & 0.729 \\
\hline \multirow[t]{2}{*}{ Smoking* in the college } & Yes & $54(70)$ & $40(56)$ & \\
\hline & No & $23(30)$ & $32(44)$ & 0.065 \\
\hline \multirow[t]{2}{*}{ Smoking* cigarettes } & Yes & (49) 64 & (58) 81 & \\
\hline & No & (28) 36 & (14) 19 & 0.022 \\
\hline \multirow[t]{2}{*}{ Smoking* other product (shisha) } & Yes & $50(65)$ & $40(56)$ & \\
\hline & No & $27(35)$ & $32(44)$ & 0.242 \\
\hline \multirow[t]{3}{*}{ The *influence of your smoking } & Friends & $4862)$ & $50(69)$ & 0.142 \\
\hline & Family & $17(22)$ & $18(25)$ & \\
\hline & Others & $12(16)$ & $4(6)$ & \\
\hline \multirow[t]{2}{*}{ *Did you receive any advice to stop smoking } & Yes & $48(62)$ & $23(32)$ & \\
\hline & No & $29(38)$ & $49(68)$ & 0.000 \\
\hline
\end{tabular}


Am. J. Infect. Dis., 7 (2): 45-50, 2011

Table 3: Knowledge of students of both colleges

\begin{tabular}{|c|c|c|c|c|c|c|c|c|}
\hline & & \multicolumn{2}{|c|}{ Medical college } & \multirow{2}{*}{$\begin{array}{l}\text { Total } \\
128 \\
(\%)\end{array}$} & \multicolumn{2}{|c|}{ Literature college } & \multirow{2}{*}{$\begin{array}{l}\text { Total } \\
124 \\
(\%)\end{array}$} & \multirow[b]{2}{*}{$P$ value } \\
\hline & & $\begin{array}{l}\text { Smoker } \\
\mathrm{N}=77(\%)\end{array}$ & $\begin{array}{l}\text { Non smoker } \\
\mathrm{N}=51(\%)\end{array}$ & & $\begin{array}{l}\text { Smoker } \\
\mathrm{N}=72(\%)\end{array}$ & $\begin{array}{l}\text { Non smoker } \\
\mathrm{N}=52(\%)\end{array}$ & & \\
\hline \multirow[t]{2}{*}{ Did you receive any advice to stop smoking?* } & Yes & $48(62)$ & ----- & 48 & $23(32)$ & ---- & 23 & 0.000 \\
\hline & No & $29(38)$ & ---- & 29 & $49(68)$ & --- & 49 & \\
\hline Did you get information about & Yes & $77(60.1)$ & $51(39.9)$ & 128 & $1(20)$ & $4(80)$ & $5(4)$ & 0.074 \\
\hline smoking in your collage? & No & $0(0)$ & $0(0 \%)$ & 0 & 71(59.7) & $48(40.3)$ & 119(96) & \\
\hline Did you know that smoking is a & Yes & $77(60.1)$ & $51(39.9)$ & 128 & $67(57.7)$ & $49(42.3)$ & $116(93.6)$ & 0.704 \\
\hline risk factor for health problem & No & $0(0)$ & $0(0)$ & 0 & $5(62.5)$ & $3(37.5)$ & $8(6.4)$ & \\
\hline Do you know that physical & Yes & $77(60.1)$ & $51(39.9)$ & 128 & $45(51.7)$ & $42(48.3)$ & $87(70.1)$ & 0.221 \\
\hline activity reduce smoking & No & $0(0)$ & $0(0)$ & 0 & $27(72.9)$ & $10(27.1)$ & $37(29.9)$ & \\
\hline Do you know & Yes & $27(71.0)$ & $11(29)$ & $38(29.6)$ & $10(66.6)$ & $5(33.4)$ & $15(12)$ & 0.851 \\
\hline $\begin{array}{l}\text { that some types of medication } \\
\text { can reduce smoking }\end{array}$ & No & $50(55.5)$ & $40(44.5)$ & $90(70.4)$ & $62(56.8)$ & $47(43.2)$ & $109(88)$ & \\
\hline Do you know that people s & Yes & $36(100)$ & 0 & $36(28.1)$ & $27(90)$ & $3(10)$ & $30(24.1)$ & 0.52 \\
\hline moke for calming down & No & $41(44.5$ & $51(5.5)$ & $92(71.9)$ & $45(47.8)$ & $49(52.2)$ & $94(75.9)$ & 0.651 \\
\hline Do you know that people & Yes & $50(60.2)$ & $33(39.8)$ & $83(64.8)$ & $45(67.1)$ & $22(32.9)$ & (54) 67 & 0.382 \\
\hline smoke due to dependence & No & $27(60)$ & $18(40)$ & $45(35.2)$ & $27(48.2)$ & $29(51.8)$ & $56(46)$ & 0.238 \\
\hline \multirow[t]{2}{*}{ * Do you ever want to stop smoking } & Yes & $41(53.2)$ & ---- & 77 & $33(45.8)$ & --- & 72 & 0.366 \\
\hline & No & $36(46.8)$ & ----- & & $39(54.2)$ & --- & & \\
\hline \multirow[t]{2}{*}{ Does the info enough to stop smoking } & Yes & $23(46.9)$ & 26(53.06) & $49(38.2)$ & $3(60)$ & $2(40)$ & $5(4)$ & 0.578 \\
\hline & No & $54(68.3)$ & $25(31.6)$ & $79(61.8)$ & $69(57.9)$ & $50(42.01)$ & $119(96)$ & 0.141 \\
\hline
\end{tabular}

Table 4: The student's opinion about smoking prevention

\begin{tabular}{|c|c|c|c|c|c|c|c|c|}
\hline & & \multicolumn{2}{|c|}{ Medical college } & \multirow[b]{2}{*}{$\begin{array}{l}\text { Total } \\
128 \\
(\%)\end{array}$} & \multicolumn{2}{|c|}{ Literature college } & \multirow[b]{2}{*}{$\begin{array}{l}\text { Total } \\
124 \\
(\%)\end{array}$} & \multirow[b]{2}{*}{$P$ value } \\
\hline & & $\begin{array}{l}\text { Smoker } \\
\mathrm{N}=77(\%)\end{array}$ & $\begin{array}{l}\text { Non smoker } \\
\mathrm{N}=51(\%)\end{array}$ & & $\begin{array}{l}\text { Smoker } \\
\mathrm{N}=72(\%)\end{array}$ & $\begin{array}{l}\text { Non smoker } \\
\mathrm{N}=52(\%)\end{array}$ & & \\
\hline Agree with Smoking prevention & Yes & $62(56.4)$ & $48(43.6)$ & $110(85.9)$ & $17(25.3)$ & $50(74.7)$ & $67(54)$ & 0.000 \\
\hline Prohibition under 18 years & No & $15(83)$ & $3(16.6)$ & $18(14.1)$ & $55(96.4)$ & $2(3.6)$ & $57(46)$ & 0.051 \\
\hline Agree with Smoking prevention & Yes & $45(54.8)$ & $37(45.1)$ & $82(64)$. & $27(60)$ & $18(40)$ & $45(36.2)$ & 0.577 \\
\hline in the restaurants & No & $32(69.5)$ & $14(30.4)$ & $46(36)$ & $45(56.9)$ & $34(43.03)$ & $79(63.8)$ & 0.162 \\
\hline Agree with prevention of smoking & Yes & $57(58.7)$ & $40(41.2)$ & $97(75.7)$ & $37(51.3)$ & $35(48.6)$ & $72(58)$ & 0.340 \\
\hline advertising activity & No & $20(64.5)$ & $11(35.4)$ & $31(24.3)$ & $35(67.4)$ & $17(32.6)$ & $52(42)$ & 0.795 \\
\hline Agree That medical staff as have a & Yes & $69(57.5)$ & $51(42.5)$ & $120(93.7)$ & $27(40.2)$ & $40(59.7)$ & $67(54)$ & 0.024 \\
\hline $\begin{array}{l}\text { vital role to play in advising } \\
\text { patients to stop smoking }\end{array}$ & No & $8(100)$ & 0 & $8(6.3)$ & 45 (78.9) & $12(21.1)$ & $57(46)$ & 0.151 \\
\hline
\end{tabular}

The opinion of students of both college (Table 4) in relation to the tools that could be exhibited for smoking prevention show statistical difference between them, revealed in the answers of $85.9 \%$ of medical and only $54 \%$ of literature students being agreed with smoking prohibition under 18 years with ( $\mathrm{p}$ value 0.000 ) and those who agree with prevention of smoking advertising activity were $75.7 \%$ of medical and $58 \%$ of literature students ( $\mathrm{p}$ value). On the other hand $(93.7 \%)$ of medical and $54 \%$ of literature students ( $\mathrm{p}$ value) agree that medical staff have a vital role to play in advising patient to stop smoking.

\section{DISCUSSION}

The relatively high prevalence rates of current smoking among university students of the studied sample of both medical $(51.7 \%)$ and literature $(48.3 \%)$ college in Iraq which was much more higher than it's prevalence among students of universities in surrounding countries, in Riyadh (37\%) (Taha et al., 1991), Jordan (Balls, 1962), 34.4\% in Kuwait (Taha et al., 1991), 24.8\% (males) in Syrian Arab Republic (Al-
Kaabba et al., 2011) and 22.1\% (males) in Turkey (Merdad et al., 2007). this may be explained as one of consequences of the overall unusual conflict situation that the youth were already living within during the last few years following the events contributed to the war of 2003 against Iraq.

Smoking frequency found to be much higher among male $(81.8 \%)$ than female $(18.2 \%)$ among students of both college in this study, mostly due to the cultural and traditional norms of Iraqi and Arabic nations where smoking being appreciated as an unacceptable and undesirable manner among women in general regardless of their age group. We found that the risk of initiation of smoking increased with the trait anxiety score. Given that medical education causes anxiety, which negatively affects the mental health of students and that the mental health scores of students increase dramatically during the first year of this education period (Zubaid et al., 2004), medical education may possibly have an indirect negative effect on smoking.

Age at initiation smoking in our study being $(53.12,49,19 \%)$ of the reported current smokers were above the age 18 years for medical and Literature 
students respectively), these finding were similar to a study A study carried in the USA reported the mean age of initiation to be 18.3 years among medical and nursing students (Maziak et al., 2004). Yet these rates were lower than the rates in a study in Saudi Arabia where about 59\% started smoking at or above the age of 18 years ( Merdad et al., 2007), whereas in another study in secondary schools $83.7 \%$ of the current smokers started at age 15 years or below (Aktekin et al., 2001).

The influence of friends as a source of first cigarette found to be tremendous in this study related to (62\% medical, 69\% literature) of current smokers followed by family members representing (22\% medical, $25 \%$ literature), since most smokers often have friends and family members who smoke and therefore engaged in risk taking behavior (Abolfotouh et al., 1998; Patkar et al., 2003).

Both smokers and non smokers were aware of the health hazards of smoking the data of this study reveal that most of the university students of both groups (medical and literature) have good knowledge about the harmful effects of smoking being a risk factor for many health problems, with some differences between these groups. Medical students were more knowledgeable (100\%) than students of the Literature College (90\%), which can probably be attributed to the positive impact of the medical information available to medical students. In a previous study of secondary school students in the Asir region they revealed that Science students were more knowledgeable about the effects of smoking than Literature students and attributed that finding to the fact that they knew more about the physiology and pathophysiology of the human body.

Even though students of both colleges have knowledge of the harmful effects of smoking and generally a favorable attitude towards public measures against the habit being tested in this study by positive responding to smoking prevention in the restaurants, prevention of smoking advertising activity, prohibition smoking under 18 years, yet smoking still constitutes a sizeable problem among them, possibly due to the addictive effect of nicotine, peer pressure, negative parental attitudes and other factors.

Health professionals have an important role to play in the fight against tobacco. As individuals they can help educate the population, as community members they can support anti-smoking policies and at a societal level, they can influence national and global tobacco control efforts (Taha et al., 1991), such role was well understood by medical students (95\%) being responded positively to the fact that medical staff could have a vital role to play in advising patients, on the other hand the statically significant differences of that of literature students ( $\mathrm{p}$ value 0.024 ) reflect the need for further participation and incorporation of medical sectors with other sectors to enhance the overall efforts applied to control smoking at community level.

However, a higher proportion of students of both colleges felt that anti smoking campaigns may not be useful in controlling smoking (Stone and Kristeller, 1992).

\section{CONCLUSION}

In spite of the high level of awareness of the harmful health effect of smoking among students of both medical and literature colleges in Baghdad university, the prevalence rates of smoking still high. The role of colleges other than medical college in providing information related to the undesirable effect of smoking still not well adapted to overcome this problem. An anti-smoking education program needs to be tailored to university students and college curriculum must have a role in such program. Changing attitude to reach the ultimate goal of changing the behavior related to smoking habits need well organized intensive campaigns whether at national level or at university level aiming at enrolment of all students and teaching staff in comprehensive program targeted the youth for better perspective of their future life and active participation in planning, implementation of initiative strategies, quitting smoking being one of them, to fulfill high quality of life for them and their families and communities.

\section{REFERENCES}

Abolfotouh, M.A., M.A. Aziz, W. Alakija, A. Al-Safy and M.S. Khattab et al., 1998. Smoking habits of King Saud University students in Abha, Saudi Arabia. Annals Saudi Med., 18: 212-216. PMID: 17341968

Aktekin, M., T. Karaman, Y.Y. Senol, S. Erdem, H. Erengin and M Akaydyn, 2001. Anxiety, depression and stressful life events among medical students: A prospective study in Antalya, Turkey. Med. Educ., 35: 12-17. DOI: 10.1111/j.13652923.2001.00726.x

Al-Kaabba, A.F., A.A. Saeed, A.M. Abdalla, H.A. Hassan and A.A. Mustafa, 2011. Prevalence and associated factors of cigarette smoking among medical students at King Fahad Medical City in Riyadh of Saudi Arabia. J. Family Community Med.,18: 8-12. DOI: 10.4103/1319-1683.78631

Al-Kilani, S., 2001. Middle East and North Africa. Regional Report. 
Balls, E.K., 1962. Early Uses of California Plants. 1st Edn., University of California Press, ISBN: 0520000722, pp: 103.

Brown, R.A., S.E. Ramsey, D.R. Strong, M.G. Myers and C.W. Kahler et al., 2003. Effects of motivational interviewing on smoking cessation in adolescents with psychiatric disorders. Tob Control, 12: iv3-iv10. DOI: 10.1136/tc.12.suppl_4.iv3

Chassin, L., C. Presson, J. Rose, S.J. Sherman and J. Prost, 2002. Parental smoking cessation and adolescent smoking. J. Pediatr. Psychol., 27: 485-496.

Gottsegen, J.J., 1940. Tobacco: A Study of Its Consumption in the United States. 1st Edn., Pitman Publishing Company, New York, pp: 279.

Heckenwelder, J. and W.C. Reichel, 2003. History, Manners and Customs of the Indian Nations Who Once Inhabited Pennsylvania and the Neighboring States. 1st Edn., Kessinger Publishing, The Historical society of Pennsylvania, pp: 149, ISBN: 9780766163638

Kulikoff, A., 1986. Tobacco and Slaves: The Development of Southern Cultures in the Chesapeake. 1st Edn., The University of North Carolina Press, ISBN: 978-0807842249, pp: 449.

Maziak, W., F. Hammal, S. Rastam, T. Asfar and T. Eissenberg et al., 2004. Characteristics of cigarette smoking and quitting among university students in Syria. Preventive Med., 39: 330-336. DOI: 10.1016/j.ypmed.2004.01.024
Merdad, L.A., M.S. Al-Zahrani and J.M.A. Farsi, 2007. Smoking habits among Saudi female university students: Prevalence, influencing factors and risk awareness. Ann. Saudi Med., 27: 366-369. DOI: 10.4103/0256-4947.51474

Patkar, A.A., K. Hill, V. Batra, M.J. Vergare and F.T. Leone, 2003. A comparison of smoking habits among medical and nursing students. CHEST, 124: 1415-1420. DOI: 10.1378/chest.124.4.1415

Stone, S.L. and J.L. Kristeller, 1992. Attitudes of adolescents toward smoking cessation. Am. J. Prev. Med., 8: 221-225. PMID: 1524858

Taha, A., A. Bener, M.S. Noah, A. Saeed and S. AlHarthy, 1991. Smoking habits of King Saud University students in Riyadh. Ann. Saudi Med., 11: 141-143. PMID: 17588069

Van Oort, F.V.A., J.V.D. Ende, A.A.M. Crijnen, F.C. Verhulst and J.P. Mackenbach et al., 2006. Determinants of daily smoking in Turkish young adults in the Netherlands. BMC Public Health, 6: 294-294. DOI: 10.1186/1471-2458-6-294

Zubaid, M., C.G. Suresh, L. Thalib and W. Rashed, 2004. Differential distribution of risk factors and outcome of acute coronary syndrome in Kuwait: Three years' experience. Med. Princ. Pract., 13: 63-68. DOI: 10.1159/000075630 